\title{
Do virtual worlds create better real worlds?
}

\author{
Mark P. Mobach
}

Received: 4 October 2006/ Accepted: 16 January 2008/Published online: 8 February 2008

(C) The Author(s) 2008

\begin{abstract}
Over the last years, virtual reality (VR) has been said to offer promise for design visualisation and has started to be included in participatory design methodology. This research provides an overview of the use of VR in architectural design and organizational space design, and explores how this application can be integrated with participatory design. The effects of the proposed integration of participatory design, VR, architecture and organization were studied in two pharmaceutical case studies. It was assessed whether the participants actually changed the design and to what extent this affected staff satisfaction and construction costs. The results show that the design was changed, staff satisfaction improved, and costs were reduced.
\end{abstract}

Keywords Architecture - Business practice . Organization · Participatory design .

Immersive virtual reality

\section{Introduction}

The use of virtual reality (VR) in the presentation and assessment of architectural design is not new. Architectural design review can be considered as one of the prime uses of $\mathrm{VR}$, enabling the user to visualise designs before scale models have been built, or even making these models redundant (Wilson 1999; Karaseitanidis et al. 2006). Moreover, the technological developments of the last three decades have allowed current designers and users to walk

M. P. Mobach $(\bowtie)$

University of Groningen, Faculty of Economics and Business,

P.O. Box 800, 9700 AV Groningen, The Netherlands

e-mail: m.p.mobach@rug.nl

URL: http://www.rug.nl/staff/m.p.mobach/research through a new building before it has actually been built, experience the atmosphere, assess the quality, and change the architectural design if necessary. VR also offers applications for organizations. Several studies have confirmed that VR has considerable potential for applications in the area of workplace design (Ehn et al. 1996; Wilson 1999; Davies 2004) and the interactive design of manufacturing processes (Fisher and Coutellier 2007; Jayaram et al. 2007).

The goal of this research was to determine the effects of a participatory design approach supported by VR for the construction of two community pharmacies. The use of VR in participatory design resulted in a comparison between (the desire to change) the old organization and the expected qualities of the new workplace design. The research assessed whether VR made participants change a particular design and to what extent this affected staff satisfaction and construction costs.

\section{Background of the study}

\subsection{VR for architectural design}

The construction industry traditionally uses two dimensional visualisation techniques (North 2000). Currently, architects combine freehand sketching on paper, electronic sketching, paper maps, photographs, computer photo imaging, 3D physical models, 3D digital models (Whyte 2002) as well as VR to communicate their design ideas; methods not any different from those used by other planning professionals (Al-Kodmany 2002). Architects, however, still use pen and paper techniques during the early design phase of their projects. Some have argued that VR may constrain creative work as it limits the freedom of 
action in this phase (Safin et al. 2005). Others have counter-argued that computers can enhance the creative process in architecture (Greenburg 1991); VR has the potential to be highly engaging and interactive (Newby 1993). The general advice is to keep VR simple, because it can be confusing if too much information is presented at once (Levy 1995) and if VR is kept simple designers can respond more easily to the tight timelines and cost controls of organizations (Pietsch 2000). Many studies have identified the benefits of using VR for architectural design. For instance, VR is said to have a positive influence on the qualities of architectural design: it stimulates the inclusion of behavioural issues into architecture (Furness 1987), offering the possibility to capture a high degree of realism and interaction because changes can be made instantly (Airey et al. 1990; Van Wijk and de Vries 1999). Further, it allows decision-makers to catch a glimpse of a possible future (Stoker and Fellow 1992), to assess the quality of their ideas (Lansdown 1994) or to improve their conceptual design (Mcfadzean 2000). In addition, VR stimulates cooperation (Frazer 1998), it is easy to use in design assessment and change (Titman 1995), and can otherwise be broadly applied in the areas of real estate and housing (Schmitt 1993; Frazer 1995; Tschumi 1995; Schmeltzer and Roelen 1995; Leclercq and Martin 2005). Moreover, with its instrument of architectural walkthroughs, VR has a positive influence on user friendliness and the reduction of design mistakes (Brooks 1989; Larijnai 1993; Zahniser 1993; Mahoney 1994), while it also helps in forecasting the possible effects of a design in its early phases and stimulates stakeholder commitment (Achten and Turksma 1999; Pialot et al. 2006). There are three other studies that provide a context in which the potential contribution of VR to architectural design is demonstrated:

1. At the beginning of the 1990s, the use of VR was crucial in convincing architects to remove a wall in the design of a university building in Chapel Hill (Rheingold 1991). The walkthrough convinced the architects that the wall was clearly in the wrong place and so it was removed in the design.

2. In the middle of the $1990 \mathrm{~s}$, a study was conducted at the University of Washington, which compared the design work quality of two groups of US architectural graduates, one using VR and one not using VR (Campbell and Wells 1994). It was concluded that VR improved the students' design quality. What was still lacking, however, was a sophisticated, immersive world-building toolkit for architects in virtual environments and VR systems, which could accommodate multiple participants and real-time communication.

3. At the end of the 1990s, a study of the design process of a Swedish university laboratory in Lund compared an application of VR in a computer aided virtual environment (CAVE) with traditional design sessions in which ideas were collected by means of paper and pencil (Fröst and Warren 2000). It was concluded that VR provided a method that enabled participants to formulate, analyse, test, and realise their ideas in a more efficient manner.

In other studies it is argued that the use of VR in architectural design has additional benefits because:

- It extends the depth of one's knowledge and experience (Tufte 1997).

- It brings spatial reality to our consciousness (Furness 1987).

- It is extremely helpful whenever the real world site is unavailable (Witmer et al. 1996).

- It allows a client to see and use a project before its actual construction (Conway and Giuliano 1995).

- It provides insight into the complex routes in building designs (Clarkson et al. 2000).

- It offers instant clues about the performance of a design (Al-Kodmany 2002).

The above studies have shown many benefits of the use of VR for architectural design. However, they only represent empty buildings. It is yet unclear how VR can be used in the connection between organization and architecture in such a way that it may actually improve the performance of organizations that construct or reconstruct their buildings.

\subsection{VR for the design of organizational space}

Every day, in countless numbers of organizations all over the world, managers make design decisions about new buildings. Generally, these managers do not construct or reconstruct these premises themselves. They are mostly lay decision-makers, lacking experience and expertise in architectural design. The construction or re-construction of a building however, is an important issue. It has an impact on business processes, because building and organization are very much intertwined. In this so-called design of organizational space, architectural design is combined with organizational design (Mobach 2007). Space can either hinder or facilitate business processes, and by doing so, they affect business performance. It is pre-supposed here that the design of organizational space is an important management task. However, managers do not like to make decisions about real estate and facilities (O'Mara 1999). It is therefore not surprising that currently architects dominate the decision-making process with respect to a building's interior or exterior. VR has the potential to capture the attention of the managers in the performance of 
this interdisciplinary task. In 1998 and 1999 the CoBuild workshop series dealt with the integration of information, organization and architecture (Streitz et al. 1998, 1999). One of its main conclusions was that such an integration provides designers with a powerful design tool. VR has the potential to integrate these different areas and to improve the communication and co-operation in design groups as well as the sustainability and flexibility of a building design. Management participation has the potential to improve the functionality and quality of the design as well as user commitment and satisfaction.

However, when using VR, architects hardly ever include intelligent agents or avatars (Verrier 2006) in their VR models and only very rarely do they integrate factual information on the performance of a business. Just a few exceptions can be found (Brogan et al. 1998; Rickel and Johnson 2000). In 2005 the virtual concept conference (Fischer and Coutellier 2005) confirmed that the integration of architectural models, business information, and multiagent behaviour remained limited (Rigot-Müller 2005; Lourdeaux et al. 2005). This is remarkable since the visual display of quantitative data has many advantages over classic forms of presentation (Tufte 1983), such as common paper business reports and architectural drawings. The use of VR can be easily combined with complex data, such as business data. Moreover, it can be expected that societal developments will push technological developments to a higher plane. To our children and the generations to come, VR will be a normal part of their lives. The scene in which Elijah Wood, the actor that plays Frodo Baggins in the award wining trilogy 'The Lord of the Rings', and the digitalised Gollum touch, illustrates the blurring boundaries between the virtual and the real world. Technology is being increasingly absorbed into the tangible world; it is becoming part of what we all take for granted (Russell et al. 2005; Streitz et al. 2007). As a result, a new generation of managers may emerge: people to whom VR is normal, and who are spoilt by the hyperrealism created by animations in the gaming and filming industries. With these possible developments in mind and the relatively scarce amount of literature in this area, it was decided to use VR in the participatory design of organizational space. This approach does not only involve an architectural model of the building but also includes multi-agent behaviour of staff and customers as well as data on the business performance of the old organization. These are the elements that form the ingredients for a participatory design session.

\subsection{Participatory design}

Participatory design gives the people who are affected by a change in the workplace a chance to influence the design process (Davies 2004). The design process can then be regarded as a co-operation between the workers on the one side and the management, architects and others involved in the design decisions on the other. This design approach can be fruitfully combined with VR (Bruno et al. 2005). Studies in architecture have also suggested that participatory design results in financial and qualitative advantages for all participants (Mogensen and Shapiro 1998; Büscher et al. 2001).

Generally four advantages can be expected. The first one is that the involvement of workers is a serious design test. The workers of the work floor have the expertise and the motivation to make a serious assessment. The planned changes will affect their future work and not necessarily that of those in the higher organizational layers (Davies 2004). Secondly, worker involvement increases the organization's commitment to the design (Davies 2004). The participant becomes a 'faithholder', which creates high degrees of trust (Luoma-aho 2005). The participant also becomes an 'accessory' in the decision-making process. Once the decision is made, it is harder for the participants to reconsider it. Thirdly, the participatory design approach leads to emancipation (Jackson 2000). It allows the lays (non architects) to understand the architectural design and imagine possible consequences (Mobach 2007). Finally, participatory design offers those who are affected by the design but initially not involved in it the possibility to discuss the consequences (Ulrich 1983), for example, the visitors of a pharmacy.

A possible pitfall of participatory design in the context of organizational spaces is that the debate remains topdown; a diktat issued by the architect and/or the management. In order to make the session run smoothly a facilitator is required (Davies 2004), a person who is in control of the quality of the debate. A debate should not only include the opinions of the powerful decision-makers, for instance, the architect and the management. It should also include the opinions of the workers who are affected most heavily but whose involvement is not self-evident in all organizations. During this research project the role of facilitator in the participatory design session was performed by the researcher.

\subsection{The FArMa-project}

In this project the relations among the pharmacy, architecture, and management (FArMa-project) were studied in the Netherlands. The project sought to improve the quality of the pharmacy buildings and organization in the area of community pharmacy practice. To this end, a discussion about the current and future state of a pharmacy building and organization was organized and combined with 


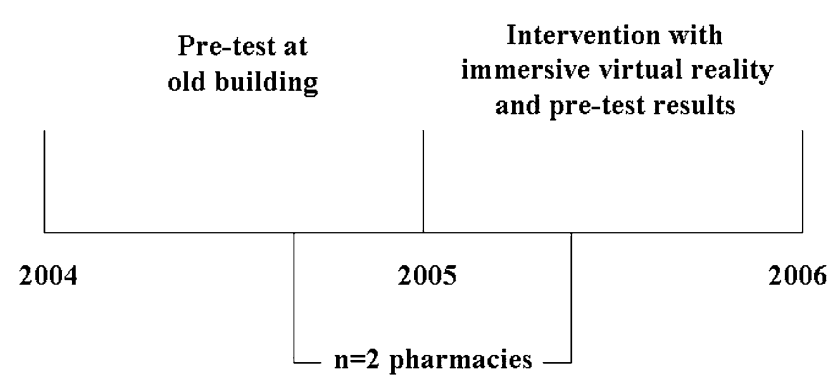

Fig. 1 Design of the study

immersive virtual reality. The project was an initiative of the Faculty of Economics and Business at the University of Groningen in co-operation with the Royal Dutch Association for the Advancement of Pharmacy (KNMP), the Scientific Institute for Dutch Pharmacists (WINAp), and the foundation Nicolaas Mulerius fund. It was supported by the centre for high-performance computing and visualisation (HPC/V) and the department for application development both at the Donald Smits Center for Information Technology (CIT) of the University of Groningen, the Dutch federation of patients and consumer organizations (NP/CF), the consultancy firms Argo and AMP, the Centre for Light Architecture (CLA), Peutz consulting engineers, ORBIT architects, Profarmaplan architects, Lloyds apotheken, and the Netherlands board for hospital facilities. A case study design was applied in which participants evaluated an existing pharmacy design and a virtual model of a new design (Fig. 1). A case study is the preferred research strategy when 'how' or 'why' questions are being posed, when the researcher has little control over the events, and when the focus is on contemporary phenomena within some real-life context (Yin 2003). Two studies, hereafter referred to as cases, were assessed; the launch of a new concept store for pharmacies of a large European pharmaceutical company entering the Dutch market (case 1) and the re-location of an independent pharmacy (case 2).

The remaining structure of this article describes the methods applied and the results. The methods were focussed on the organization of the participatory design session and the use of VR in participatory design combined with organizational behaviour. The results describe the design changes proposed, the cost analysis, and the evaluation of the participatory design session.

\section{Methods}

\subsection{Introduction}

In this study the participatory design approach comprised a session in which architects, management, and workers

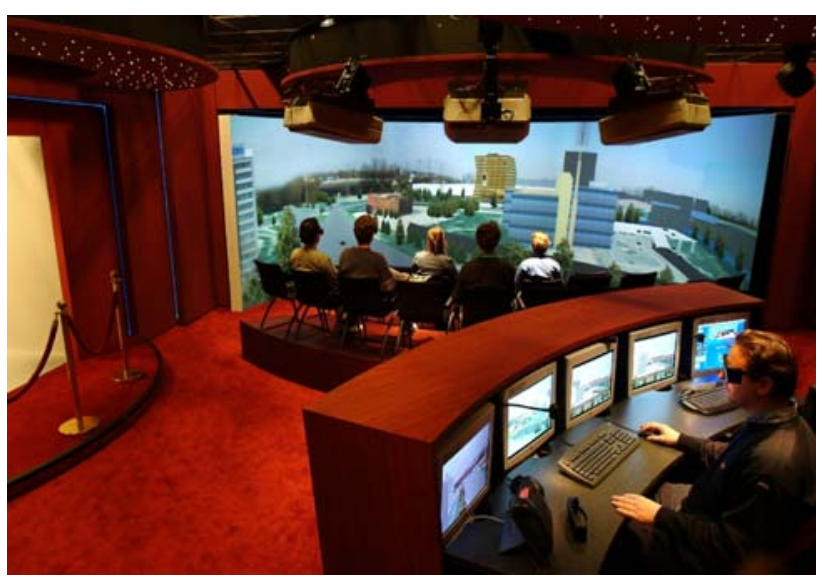

Fig. 2 The virtual theatre at the University of Groningen

discussed and decided co-operatively on changes to be made. The approach included VR and behavioural data from the organization. It combined facts, figures, and photos of the current state of the pharmacy with images of a future state of a new pharmacy depicted with the aid of immersive virtual reality, presented in a virtual theatre at the University of Groningen in the Netherlands in 2005 and 2006 (Fig. 2). It was agreed that the participants would come to Groningen when they regarded the 2D drawings as finalised. We therefore start from the assumption that the 2D drawings were well considered and the participants were fairly satisfied with the designs chosen. The new participatory approach; however, was expected to contribute to a new and improved corporate debate aimed at the optimum design of the organizational spaces, and, by doing so, tease out some design changes. The study conducted at the virtual theatre was action research: the researcher actively participated in the discussion with the management, architects and workers.

\subsection{Organization of the participatory design session}

\subsubsection{Introduction}

All participants were invited to the virtual theatre in Groningen for a day. The participatory design session consisted of a short introduction in a classroom in the morning, followed by a full immersion in the virtual world, a lunch break, and an elaborate assessment of the design in the virtual theatre in the early afternoon. The programme concluded with an evaluation in a classroom later in the afternoon. The basic idea was to immerse the participants in the new workplace design. The lunch allowed the participants to be fresh again for a thorough and critical debate in the afternoon about the expected qualities of the design. The researcher actively participated in this discussion in 
order to stimulate a fair debate and facilitate a critical reflection on practical assumptions or conclusions.

\subsubsection{Introduction in the morning}

At 10 a.m. all participants had gathered in the class room. The main questions addressed during the introduction were: 'What is the quality of the design?' and 'Why are we here today?'. The participants started by completing a custom-made questionnaire about the quality of the design. The questionnaire consisted of 35 and 38 items for case 1 and 2 respectively. A 10-point scale was used to give a report mark per item. Next, the researcher briefly explained the research and the day schedule. At the end of the introduction the participants were invited to go to the virtual theatre.

\subsubsection{Immersion in the morning}

From 10.30 to 12.00 a.m. the participants were immersed in the new workplace design. The main questions addressed during this immersion were: 'What will the new building look like exactly?' and 'Why does it look the way it does?' The participants made a full screen virtual walkthrough in both the 'empty' architectural design and in the architectural design with multi-agents (Figs. 3, 4). The virtual walkthrough consisted of three main areas: the area where customers wait, the area where the staff dispense prescriptions, and the over-the-counter (OTC) area where customers look at or buy non-prescription drugs. In the morning the workers 'just' listened to the ideas of the architect and management; no discussion was allowed. They could only ask questions to further elaborate their understanding of the design and the intentions of the designers. From 12.00 to 13.00 p.m. the group had a lunch break.

\subsubsection{Assessment in the early afternoon}

From 13.00 to 15.00 p.m. the participants discussed the supposed quality of the design in the virtual theatre. The discussion agenda set was based on the organizational data from the pre-test. The main question addressed was: 'Is it improving?' Again the virtual walkthrough consisted of the waiting area, the prescription area, and the OTC area. In this approach, all different sorts of data from the organization were compared with the 'problem solving effects' of the virtual new design. In the waiting area the participants discussed the expected customer behaviour during the wait and the interaction between customer and working staff at
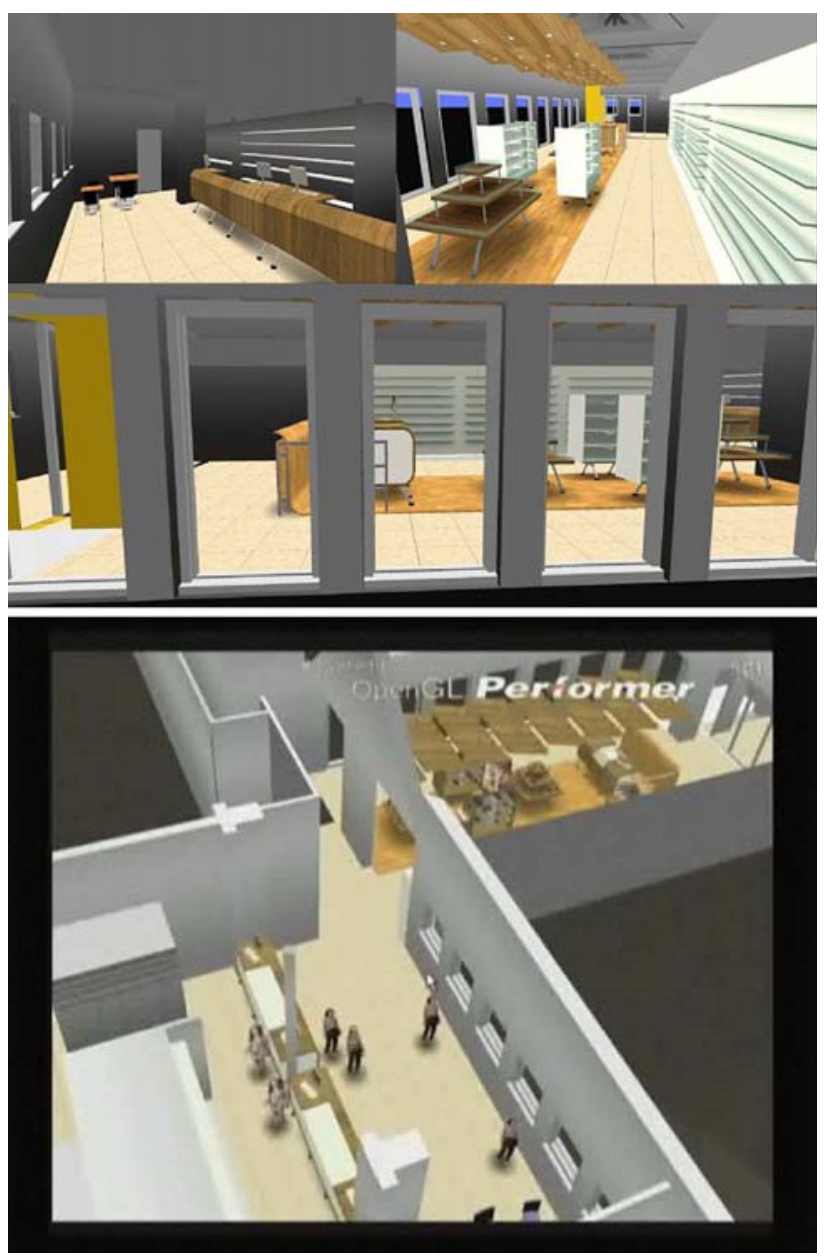

Fig. 3 Stills of the 3D design of case 1

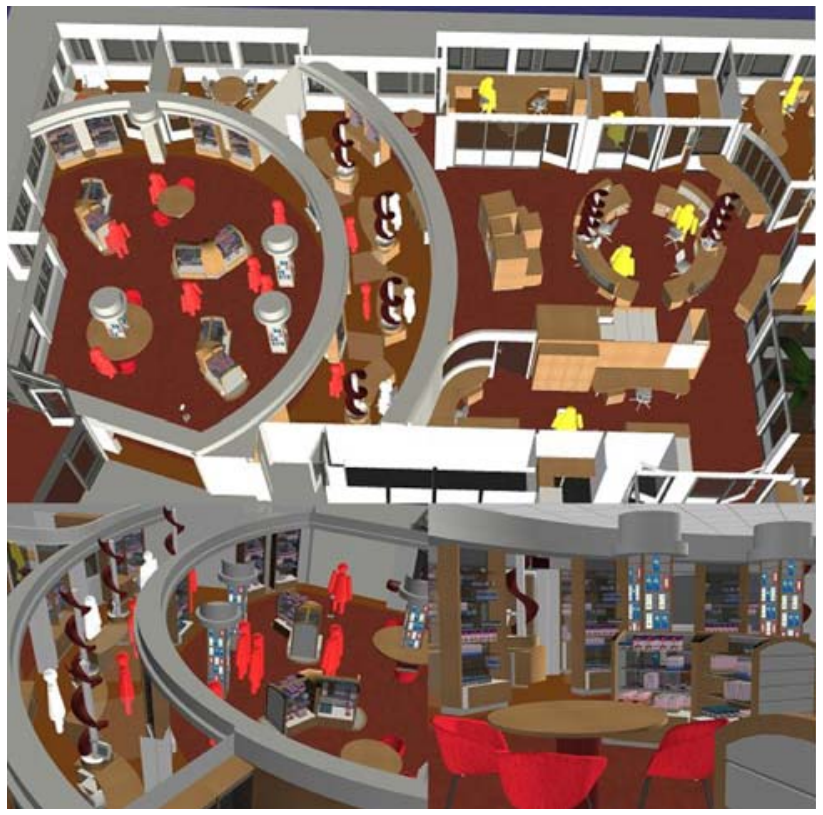

Fig. 4 Stills of the 3D design of case 2 
the counter. In the prescription area the discussion focussed on the planned working systems for the front office and back office staff, and in the OTC area the participants discussed the expected customer behaviour, in this case behaviour to increase sales and to distract customers during their wait.

\subsubsection{Intervention in the afternoon}

From 15.00 to 15.30 p.m. the participants proposed design changes. This was the final activity in the virtual theatre. The main questions were: 'Where would you like to change the design?' and 'What would be the costs of these changes after completion?' In both cases the participants could decide on interventions to be made. The researcher documented the proposed changes and related arguments. All participants were invited to make detailed cost estimations. The architect made a cost estimation of the architectural changes and the participants were asked to make a cost calculation of their own efforts, including staff expenses, the cost of renting the virtual theatre, lunch, and transport.

\subsubsection{Evaluation in the afternoon}

From 15.30 to 16.00 p.m. the participants gave their opinion about the usefulness of this participatory design approach combined with VR. The main questions were: 'Did VR change your opinion of the design?' and 'Was it a useful session?'. The questionnaire about the quality of the design, which was used during the introduction in the morning, was repeated in order to determine whether the participants had developed different opinions during the day. In addition, the general satisfaction with the participatory design was measured. A 10-point scale was used to judge this item with a report mark. In addition, the respondents were invited to give arguments for their judgments.

\subsection{Virtual reality in the participatory design session}

\subsubsection{Introduction}

The VR component in the participatory design session consisted of a virtual model of the new workplace design. The software by which this model was created allowed the computer programmer in the cockpit to create different spaces in real time, enabling the participants to experience them instantly. Several extras were added to this model: multi-agents and sheets as jpg-images containing organizational data as well as digital images of the old pharmacy.

\subsubsection{Virtual theatre}

The virtual model was displayed in the virtual theatre. The theatrical structure allowed 20 people to assess the design quality simultaneously. In this theatre stereo images were projected on a cylindrical screen by means of three projectors. The Open Scene Graph RekenCentrum (OSG-RC) software, developed in-house by the HPC/V, made it possible to visualise the architecture interactively. It allowed architectural elements, such as walls, desks or doors, to be moved, rotated, duplicated or removed as well as colours and materials of objects to be changed interactively. The projection was located at a position above the audience, like in a cinema. The stereo effect was created with shutter glasses, which could be switched from fully transparent to opaque. If the right glass was transparent, the left was opaque, and vice versa. The right glass was transparent when the right eye stereo image was projected, while the left glass was transparent when the left eye stereo image was projected. The refresh rate of the projectors and the shutter glasses was $96 \mathrm{~Hz}$. This frequency was sufficiently high to create an illusion of three dimensions, in this case the workplace design of two pharmacy buildings.

\subsubsection{Virtual architectural design}

By means of immersive VR a lively 3D image of the new pharmacy workplace designs was created. In case 1 the virtual pharmacy was rather basic (Fig. 3). In this model only a limited number of interior details were presented, for instance, counters, computer screens, gondolas, cabinets, shelves, and floor and ceiling panels. Only two tables with some chairs were included in the waiting area. The rest of the interior, including all office, logistical and pause areas as well as the main architectural structures, was kept empty or white, resulting in relatively large empty spaces.

In case 2 the virtual model was more elaborate (Fig. 4). Apart from the interior details worked out in case 1, this model also included, for instance, all original closets, tables and chairs, a model of the robot, chutes through which the requested medicine would fall down from a robot system, brochures on the shelf, medicine in the cabinets of the waiting area, and the queuing system, including the ticket issue and displays. The main architectural structures as well as the floor and ceiling were designed in the colours as originally intended. Consequently, this approach resulted in a highly realistic representation of the space.

It was possible to change and manipulate the shape, size, number, position, and colour of objects in real time as well as the camera position of the participants. Consequently, 
Fig. 5 A staff agent of case 1

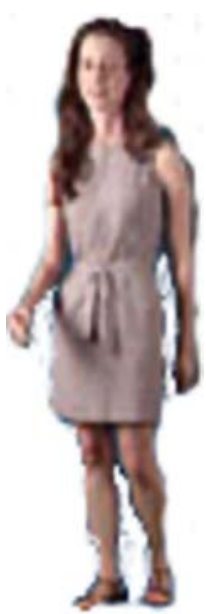

both the virtual model itself and the camera position, allowing the participants to assess the design from different angles, could be changed during the discussion.

\subsubsection{Multi-agents behaviour}

The virtual architectural design was refined with multiagents behaviour. The agents represented working staff and customers. Customer behaviour was modelled in the waiting and OTC areas and working staff behaviour in the prescription and OTC areas. The routing of the agents and timing at the counter were estimated by using a mix of the new working systems and organizational data from the pretest: a mix of waiting times, lead times, customer behaviour during the wait, and general observations. The management, the visualisation specialist, and the researcher together estimated the agents' behaviour.

In case 1 the agents were cardboard puppets representing elementary movements of humans at the pharmacy (Fig. 5). The agents were given different appearances so that the participants could understand their function in the model. Three sorts of agents were modelled and linked to a prescription customer (young woman), a non-prescription customer (man), and working staff (woman). The routing of the agents can be compared with the floor plan of case 1 (Fig. 6): prescription customer agents entered, passed the OTC-area, waited in the waiting area, moved to the counter when it was their turn, were helped and waited at the counter, and finally left, again passing the OTC-area. The working staff agents were moving between the counter and the closet directly behind the counter. Non-prescription customer agents entered, walked around in the OTC-area, moved to the counter, were helped and waited at the counter, and finally left. In this area the working staff agents were standing still at the counter. In the design the agents' movements had prefixed XYZ-positions; they more or less formed an agent formation that could be inspected from different viewpoints. Only the empty virtual architectural design could be changed.

In case 2 the agents looked like 'Playmobil@' figures (Fig. 7). Again they were given different appearances for the participants to understand their function. Three sorts of coloured tops were used to distinguish among customers (in red), front-office working staff (in white), and backoffice working staff (in yellow). In contrast with case 1, the prescription and non-prescription customers had the same appearance because in the new design of case 2 the OTC and waiting area had been fused. The routing of the agents can be compared with the floor plan of case 1 (Fig. 8): customer agents entered, moved to the ticket issue of the queuing system, moved around in the waiting/OTC-area, moved to the counter when it was their turn, were helped and waited at the counter, and finally left. In accordance with the newly defined working system, the front-office agents mainly stayed at the counter, incidentally moving between the counter and some of the closets in the counter area. The back-office agents were mainly located in the prescription area, generally sitting at one of the four workplaces in the circular working centre or moving between their workplace and the closets. Three software improvements were made to enable interaction in the virtual model of case 2 . Firstly, changes were made possible in the virtual design with agents. Secondly, the movement of the interior and the underlying structure of the agent behaviour could be changed simultaneously. This allowed agents to arrive at the newly preferred location in the model. For instance, if the counter moved the agent would follow it. Thirdly, it was made possible to delete a location, including the agent behaviour linked to it. Consequently, by means of these improvements the impact of the agents' movements could be observed in real time. It should be remarked that although in case 2 these adaptations certainly improved the multi-agents' behaviour, in terms of appearance, motion and gesture the representation of the agents was still not realistic.

\subsubsection{Projection of the organizational data and digital photography}

A powerpoint-presentation was prepared containing separate sheets in jpg-format. Each presentation image combined organizational data with digital images of the former situation (Figs. 9, 10). Digital photos were made with a Canon Powershot S50. The jpg-images were imported in VR and put on the left screen, while the new workplace design was projected on the remaining two 


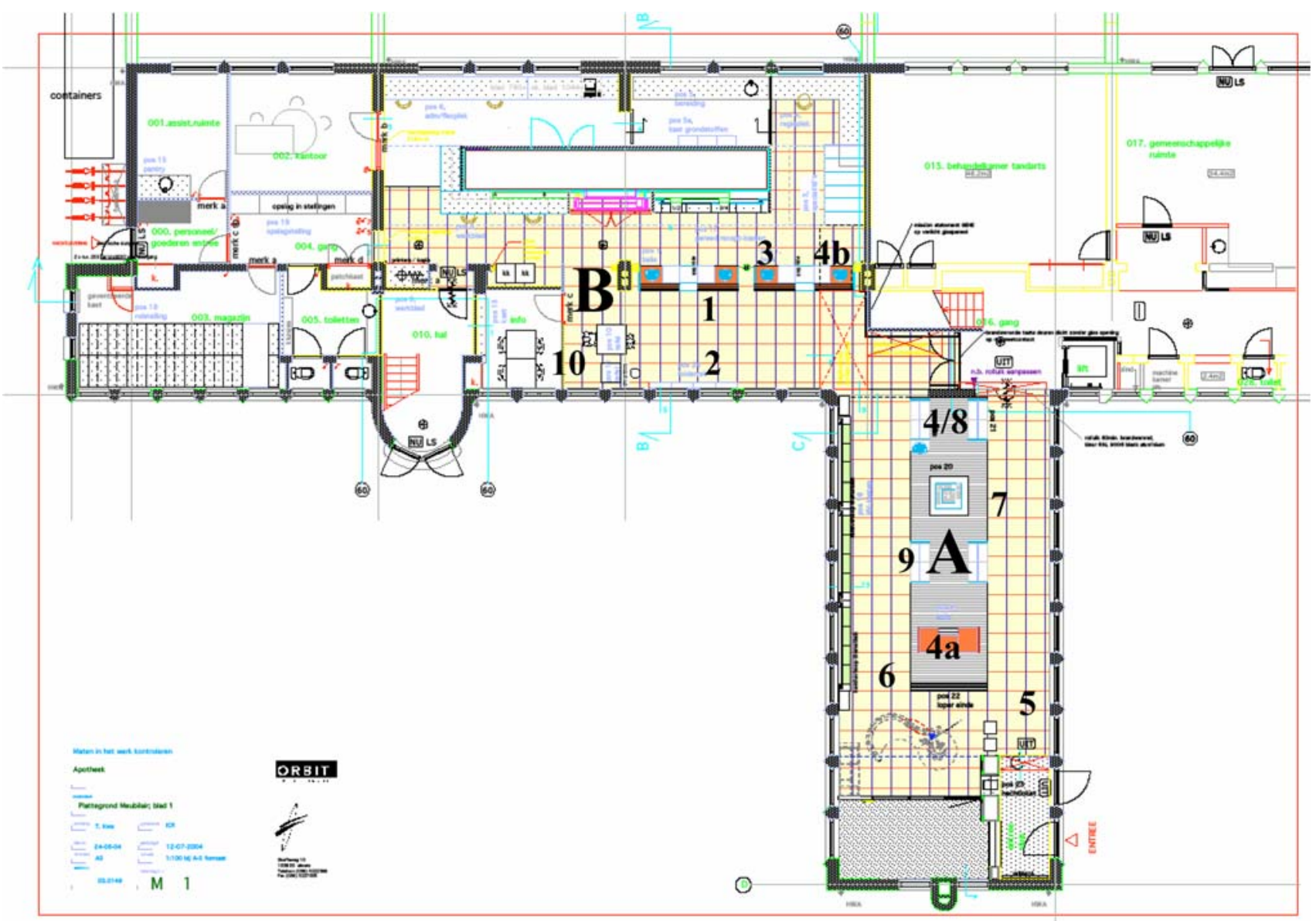

Fig. 6 The floor plan of the new pharmacy in case 1 by ORBIT architects (a OTC area, b prescription area)

screens. For most aspects of the design this approach made it possible to switch easily between the presentation image and the VR. In this way the participants were able to

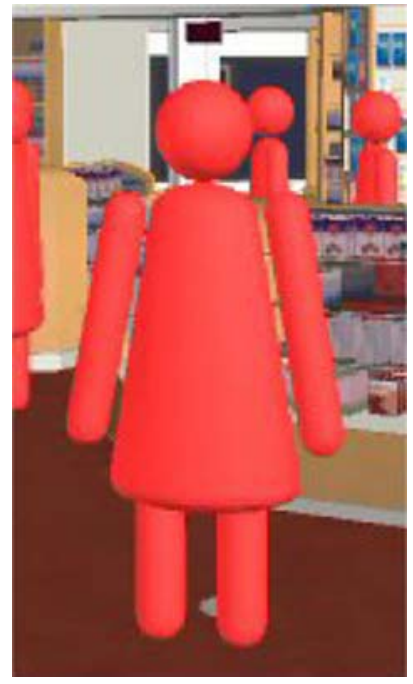

Fig. 7 Customer agent of case 2 refresh their minds occasionally, making it easier for them to perform a sharp analysis of the differences between old and new.

\subsection{Organization behaviour in the participatory design session}

\subsubsection{Introduction}

The organization behaviour component in the participatory design session consisted of the disclosure of organizational, logistical, customer, and strategic data on jpg-sheets. In this paper we decided to give a concise description of the results of the organization studies. From the above we have learned that it was the aim to determine the effects of VR on participatory design in the construction of two community pharmacies. The organization behaviour results only related indirectly to the main aim of this paper, and in particular the strategy was expected to violate the privacy of the organizations studied. The organizational, logistical and customer data dealt with the current state of the system and the 
Fig. 8 The floor plan of the new pharmacy in case 2 by ProFarmaPlan architects (a waiting area, b counter area, and $\mathbf{c}$ prescription area)

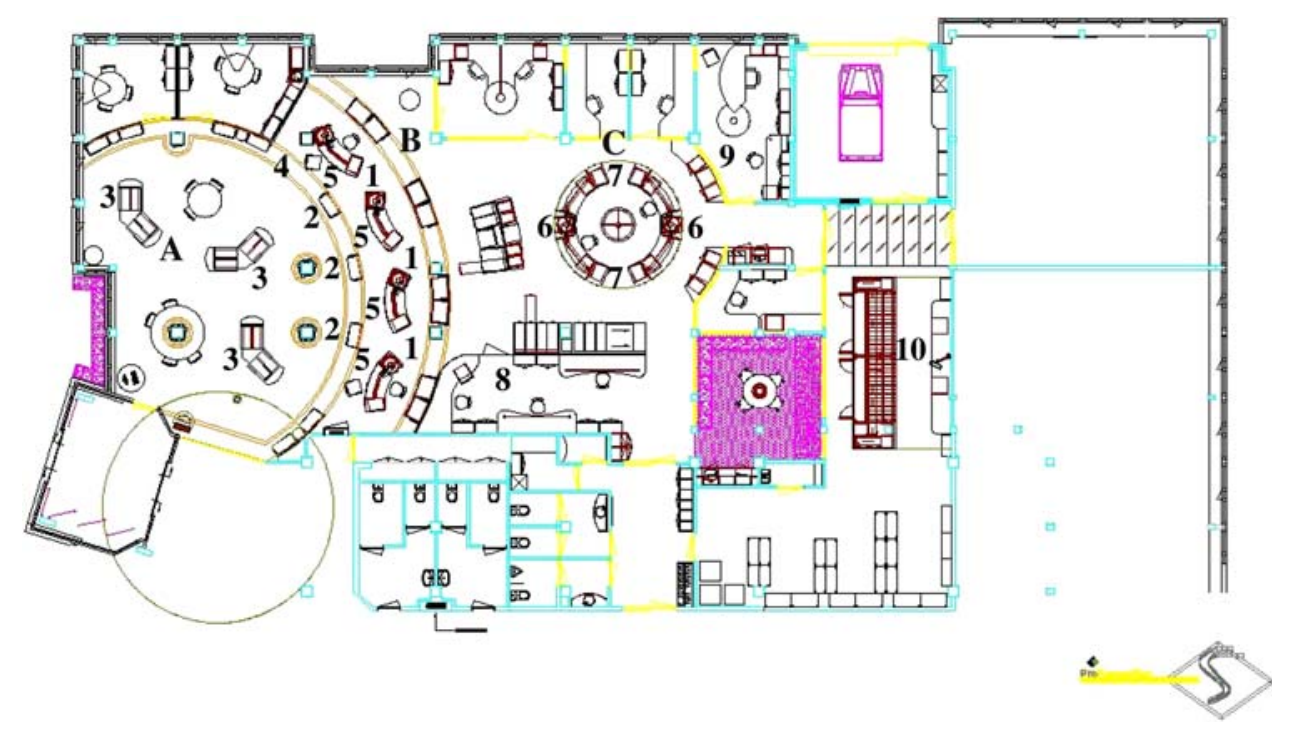

Fig. 9 Inserted personnel results of the old pharmacy in case 1

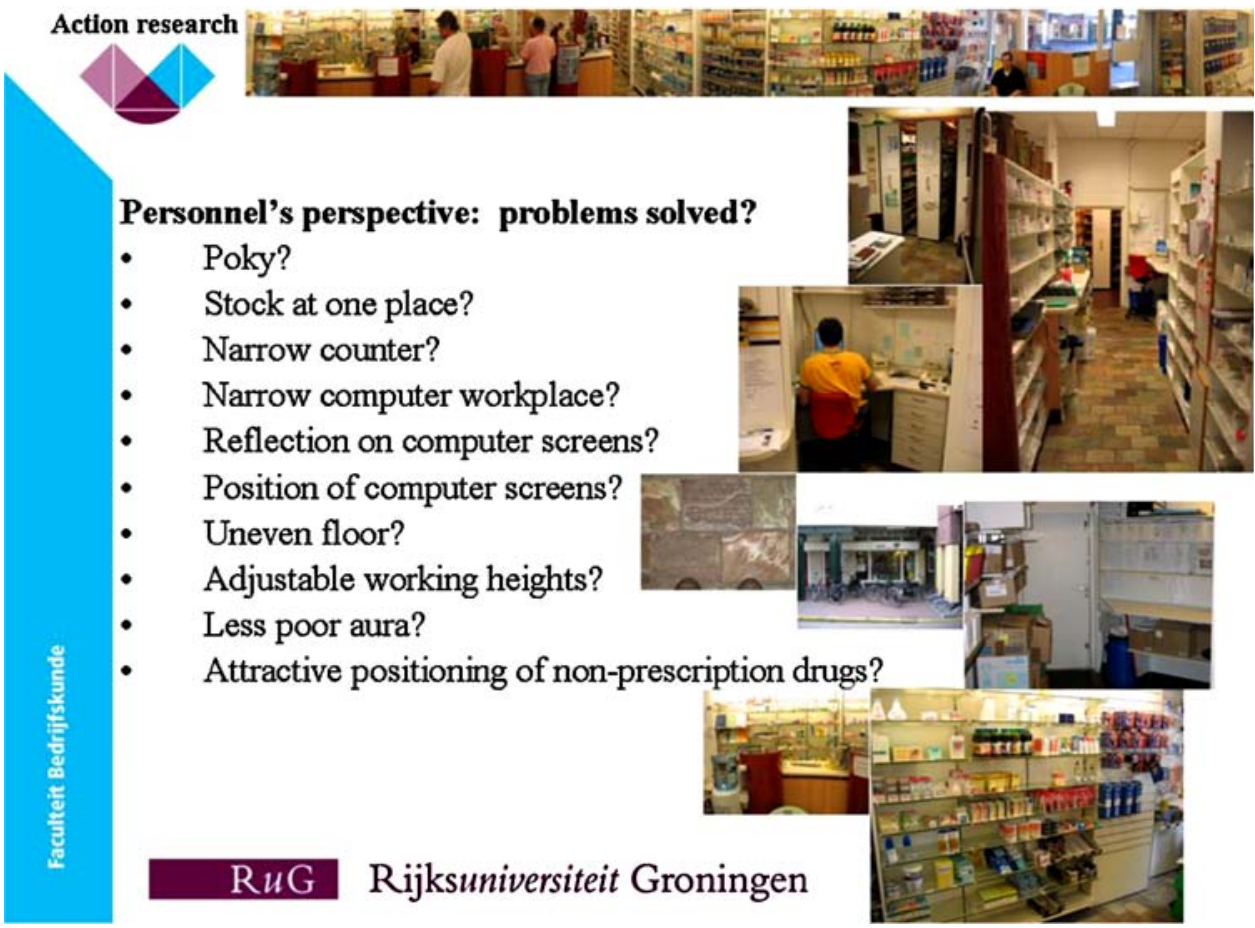

strategic data with the future state. The data were collected during a 2-month study at each pharmacy in the spring of 2004.

\subsubsection{Organizational and logistical data}

Both the organizational and logistical data were related to the old situation. They comprised personnel satisfaction, workflow, and acoustics, for both cases. The data on personnel satisfaction were collected by means of interviews and three questionnaires dealing with general satisfaction, satisfaction with the building, and staff opinion about customer satisfaction. In the data collection on workflow observational studies were combined with self-report. In the observational studies the lead times were determined. In the self-report the number and nature of tasks performed, prescriptions dispensed, customers helped, and questions asked were identified. Examination of the acoustics was aimed at determining 
Fig. 10 Inserted customer results of the old pharmacy in case 1

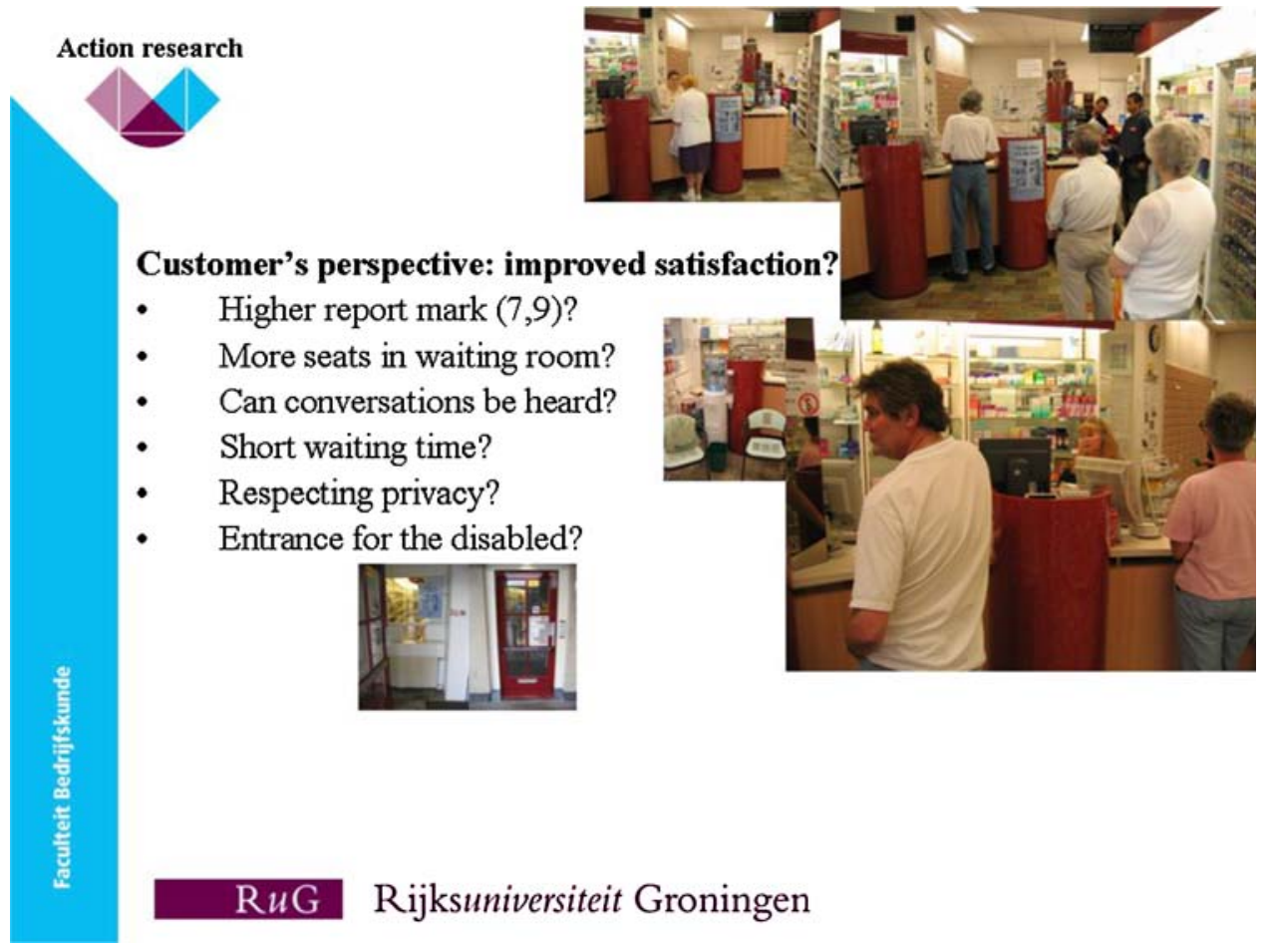

to what extent conversations in the prescription and counter areas could be heard in the waiting area. The data were obtained with a Rion sound level meter.

Although the results showed many interesting findings, the most important outcome in both cases was the problem of privacy at the counter. The staff had very serious complaints about the acoustics. They had the feeling that conversations could be heard by others waiting. The acoustic measurements confirmed this perception: waiting customers could indeed hear the conversations held at the counter.

\subsubsection{Customer data}

The customer data were also related to the old situation. The data on customer satisfaction were collected with a questionnaire, while the customer behaviour in the waiting area was determined by means of observational studies. In both cases the results again confirmed the privacy problems at the counters, although this time from the customer perspective. Also the customers had the feeling that their conversations could be heard by those who were waiting.

\subsubsection{Strategic data}

The strategic perspective was used to make the future strategy explicit. In case 1 interactive planning (Ackoff 1999) was applied and in case 2 interactive management
(Warfield 1994). These approaches facilitated a concise overview of the expected qualities of the new design. For privacy reasons only the most relevant data are given: data that were actually used in connection with the modifications made in the immersive VR.

In case 1 the work of Ackoff (1999) was followed with a focus on:

- Formulating the mess: Provide a general overview of the organization and its environment.

- Ends planning: Define the current and ideal state of the organization. In our study these two states were defined in terms products and services, communication, building, location, management, marketing, prescription drugs, non-prescription drugs, customer population, personnel, working system, and competition.

- Means planning: Define the exact organizational space properties of the concept store. In our study the focus was specifically on the properties that were expected to bring the current situation closer to the ideal one.

This approach showed that the improvement of customer satisfaction was the most important issue to the management. This issue was split into three contributions: decrease in lead times, a more inviting atmosphere to ask questions, and more space for non-prescription drugs. The first contribution was expected to be changed with a robot for logistic tasks and the second and third contributions by adapting the interior design of the concept store.

In case 2 the work of Warfield (1994) was followed with a focus on: 
- Situation: The situation involves at least one organization and includes an issue (what others have called a problem or process) that has a scope which will become clear only as the process evolves.

- Issue: The issue is likely to have bothered the organization for some time and may also have frustrated previous attempts to deal with it.

- Initial meeting goals: The initial meeting goals are established during the initial contacts among the prominent members of the organization, in this case the architect, two pharmacists, and the researcher.

- Idea writing: Idea writing is basically an exchange of ideas and is stimulated by a triggering question. A small group of participants responded in silence to this question, followed by an exchange of ideas. In this study the triggering question was: 'What is your pharmaceutical care strategy for organizational space?'

This approach showed that the management expected the most important contributions at the level of customer and working staff satisfaction. The customer should be at ease in an unconstrained atmosphere and feel free to ask questions. These criteria should be carefully worked out in the properties of the waiting area and the counter area. The staff members were defined as qualified professionals that should be supported with high-quality multifunctional workplaces; a focus on the prescription area.

\subsection{Participatory design in virtual organizational space}

The approach described was set up to determine the effects of VR in participatory design for the construction of two community pharmacies. The approach combined an application of VR for interactive visualisation of a new workplace design and multi-agents behaviour with various data gathered in the existing organizations and their buildings. All these tools and results may be regarded as the ingredients for this particular form of participatory design. The data were edited and prepared for presentation in a virtual theatre. It was expected that this approach would allow the participants to assess the supposed qualities of the virtual design of the organizational space critically and improve the original design.

\section{Results}

\subsection{Introduction}

The aim of this study was to determine the effects of this particular use of VR. These effects emerged in the design changes proposed, the costs, as well as in the evaluation of the participatory design session itself. It was shown that this new integration of participatory design, virtual worlds and organizational space had remarkable effects on the real world of the participants.

\subsection{Proposed design changes}

In the discussion the participants made various proposals. Criteria for selection of a proposal included the quality of the argument and the support for it, regardless of the function of the participants or their hierarchical position. All serious proposals, the ones that were discussed thoroughly and acknowledged by all participants, actually led to design changes. The researcher documented these proposals. In both cases the most important proposals related to privacy. The design changes proposed in case $1 \mathrm{com}$ prised ten items; each number is indicated on the floor plan (Fig. 6).

1. A privacy line on the paving tiles.

2. An audio installation for background music in the waiting area.

3. Keeping one counter unoccupied.

4. A new counter position in the layout.

5. A magnetic gate at the entrance.

6. The removal of a redundant design floor.

7. The removal of two drawers and a display.

8. A new 'information' sign at the counter.

9. An extra display for brochures.

10. An orange wall in the waiting area.

Even though the participatory design session took place very late in the design process, just four days before the concrete was put on the floor, the group decided to change ten items. From the organization behaviour data we learned that there was an urge to improve the privacy and create an atmosphere in which customers would feel comfortable to ask questions. Most of the design changes proposed related to these issues.

- Proposed changes 1-3 contributed to the privacy in the prescription area. Basically, the idea was to either increase the distance between the customers or increase the noise. This was expected to improve the problem of listening in on counter conversations of others.

- Change 4 improved customer friendliness. The OTC counter moved to a new position (4), which allowed face-to-face contact after customers' entrance. In the earlier position, which was close to the entrance (4a), customers looked at the backs of the staff when entering the building. The new position was also closer to other counters $(4 \mathrm{c})$, providing staff members with a safer workplace in cases of emergency or theft. 
- Proposed changes 5-7 referred to the fourth change and contributed to safety and aesthetics. The changed location of the counter increased the distance of the staff to the exit. Consequently, the workers' overview diminished, which was unfavourable in the light of possible theft by visitors, which in turn led to a need for a magnetic gate. In addition, the appearance of the space changed, which meant an alteration of its interior. Part of the floor design, two drawers, and a display were removed to enhance the aesthetical appearance of the space.

- Changes 8-10 contributed to the remaining categories: improved signposting, extra space for information brochures, and a friendlier, more colourful atmosphere in the waiting area respectively.

The design changes proposed in case 2 also comprised ten items; the numbers are again indicated on the floor plan (Fig. 8).

1. A glass partition between the counters.

2. The removal of closets close to the counter.

3. Making the gondolas mobile.

4. An extra queuing display.

5. A partition under each counter.

6. Adapting the computer screens to the work tops adjustable in height.

7. Placing waste paper baskets adjustable in height.

8. Introducing adjustable work tops for the office administration.

9. Extending the pharmacist's office, for it was considered too small.

10. Relocating the robot. This was expected to create more space on the working floor.

In case 2, the participatory design session took place relatively early in the construction process, approximately six months before the actual construction. Here the group also decided to change ten items. From the organization behaviour data we learned that in this case there was also an urge to improve privacy and create an atmosphere in which customers would feel comfortable to ask questions. In addition, the staff members were qualified as professionals in support of high-quality multifunctional workplaces. Most of the design changes proposed related to these issues.

- Proposed changes 1-5 contributed to privacy. The extra measures were taken in order to reduce the sight and secure a large distance between customers at the counter and in the waiting area. Customers were directed towards the waiting area and invited to shop, queue, read, talk, and play while they were waiting. These measures were expected to reduce the possibilities to listen in on counter conversations. Moreover, the partitions under the counter obstructed the view of customers under the skirts of female staff.

- Proposed changes 6-8 enhanced the ergonomics and multi-functionality of the work place. Staff members could adjust the workplace to their own height.

- Changes 9-10 contributed to the remaining categories, in this case a larger office for the pharmacist and more space on the working floor.

\subsection{Cost analysis}

In order to assess the financial benefits of this particular use of VR, all participants were asked to make a detailed cost calculation of their efforts (Table 1). The architects also made cost estimations of the architectural changes.

In case 1 the proposed design changes were estimated at $23,000 €$. The total construction costs amounted to $€$

Table 1 Observations at the participatory design session

\begin{tabular}{|c|c|c|c|c|}
\hline Case issue & Case 1 & & Case 2 & \\
\hline Response & $n=8(89 \%)$ & & $n=22(100 \%)$ & \\
\hline Cronbach's $\alpha$ & 0.96 & & 0.86 & \\
\hline Mean satisfaction with VR session & 8.1 & & 8.7 & \\
\hline Construction costs & $250,000 €$ & & $600,000 €$ & \\
\hline Costs to perform VR session & $18,000 €$ & & $23,783 €$ & \\
\hline Imaginary costs of reconstruction & $23,000 €$ & & $31,200 €$ & \\
\hline \multirow[t]{2}{*}{ Benefits } & $+5,000 €$ & & $+7,417 €$ & \\
\hline & Before VR & After VR & Before VR & After VR \\
\hline Mean report mark for new design & 6.9 & 7.4 & 6.9 & 7.8 \\
\hline Standard deviation for report mark & 0.42 & 0.48 & 0.69 & 0.29 \\
\hline No idea of the quality of the designed items & $22(n=6)$ & $8(n=4)$ & $19(n=16)$ & $7(n=6)$ \\
\hline
\end{tabular}


400,000 and the participatory design session costs to $18,000 €$, consisting of:

- $10,000 €$ for the extra work of the architect entailing 3D drawing and consultation

- $6,000 €$ for the computer animation and programming work of the HPC/V

- $2,000 €$ for the visit of the participants to Groningen and their stay at the university campus

For case 2 the proposed design changes were estimated at $31,200 €$. The total construction costs were $650,000 €$ and the costs of the participatory design session amounted to $23,783 €$, consisting of:

- $\quad 9,700 €$ for the extra work of the architect entailing 3D drawing and consultation,

- $7,250 €$ for the computer animation and programming work of the HPC/V,

- $6,833 €$ for the visit and stay of the participants in Groningen.

The total cost of both participatory design sessions came to $41,783 €$ and the estimated cost of the proposed design changes was $54,200 €$. So the total financial benefits of this participatory design were $12,417 €$. Given the financial benefits as well as other advantages to be reported, and taking into account the total construction cost of 1,050,000 $€$, it can be concluded that this particular form of participatory design is relatively cheap: less than $4 \%$ of the total construction budget.

\subsection{Evaluation of the participatory design session}

\subsubsection{Introduction}

The questionnaires in cases 1 and 2 had a Cronbach's alpha of 0.96 and 0.86 , respectively, indicating that their internal consistency was fairly good, which shows that they served as a relatively reliable source of information. The response was $89 \%$ ( $n=8$ out of 9$)$ and $100 \%(n=22)$ for cases 1 and 2, respectively; in case 1 one of the members of the management team had to leave early. Table 1 summarises and compares the results before and after the participatory design session.

\subsubsection{Satisfaction with the design before the participatory design session}

The results of the questionnaire before the participatory design session, which were based on the 2D architectural drawing, show a report mark of 6.9 for the designs of both cases. The standard deviation of the mean was 0.42 and 0.69 for cases 1 and 2 , respectively.
In case 1 most respondents, mainly workers, had problems assessing the design qualities in advance:

- Six of the eight respondents $(75 \%)$ could not estimate the quality of 22 of the 35 design items (63\%) in advance.

- Five respondents had problems assessing 20 of the 35 items $(57 \%)$.

- One respondent, the architect, could not assess two items: whether the pharmacy was functioning fine and whether the design was personnel-oriented.

- Two of the eight respondents (25\%), both managers, could assess all items in advance.

In case 2 most respondents, again mainly workers, also had problems to assess the design qualities:

- 16 of the 22 respondents $(73 \%)$ could not estimate the quality of the design of 19 of the 38 design items (50\%) in advance.

- 15 respondents had problems with 18 of the 38 items $(47 \%)$.

- One respondent, the architect, could not assess three items: the quality of the parking facilities, working pressure, and control of congestion. Moreover, he was unable to say if the new pharmacy would please other stakeholders, such as the general practitioner and the health insurance company.

- Six of the 22 respondents (27\%), two managers and four pharmacy assistants, could assess all items in advance.

\subsubsection{Satisfaction with the design after the participatory design session}

The results of the questionnaire after the participatory design session showed higher report marks: a 7.4 and a 7.8 for the designs in cases 1 and 2. The standard deviations of the mean increased slightly to .48 in case 1 and decreased substantially to 0.29 in case 2 .

- In case 1 , four out of the eight respondents (50\%) could not estimate the quality of the design of eight of the 35 design items $(23 \%)$ after the session

- In case 2, six of the 22 respondents (27\%) could not estimate the quality of the design of 7 of the 38 design items $(18 \%)$

- Nine of these respondents who could not estimate the design quality of the items after the virtual session were also not able to do so before the virtual session

- One respondent argued that only after the session the quality of the item 'lighting' could not be assessed 


\subsubsection{Comparison of satisfaction before and after the participatory design}

The difference between the total results for all respondents of the questionnaire before and after the participatory design session showed an increase in the mean report marks for all items and respondents. The paired-samples $t$ test, using a $95 \%$ confidence interval, indicated that the increase in the mean report mark was not significant for most items in case 1 and significant for most items in case 2. The standard deviation was used as a measure for common ground among the participants.

In case 1 for 35 items the situation did not improve statistically significant as a result of the participatory design:

- the mean report mark did not increase significantly, namely by 0.5 (from 6.9 to 7.4 ),

- the standard deviation showed a minor increase of 0.06 (from 0.42 to 0.48 ),

- for six items the standard deviation did not change, whereas it increased for 11 items, and decreased for 18 items,

- the standard deviation changed significantly for only 9 of the 35 items (26\%):

- it increased significantly for two items: customeroriented and information work

- it decreased significantly for seven items: mood on the working floor, mood of customers, perceived waiting time, waiting area, seats, computer work, and innovation

- for practically none of the items the possibility to make an assessment decreased

Although participatory design improved design satisfaction, this improvement was statistically not significant. The standard deviation was subject to minor changes and remained relatively stable. Therefore it can be concluded that the participatory design approach did not influence the design satisfaction and internal agreement within the group in case 1 .

In case 2 for most of the 38 items the situation improvement was statistically significant as a result of participatory design:

- the mean report mark increased significantly by 0.9 (from 6.9 to 7.8 ),

- the standard deviation decreased substantially by 0.4 (from 0.69 to 0.29 ),

- for no single item the standard deviation did not change, whereas it increased for one item, and decreased for 37 items
- the standard deviation changed significantly for 34 of the 38 items (90\%):

- it did not decrease significantly for four items: parking facilities, accessibility, counter work, and working pressure,

- it decreased significantly for all other 34 items,

- for none of the items the possibility to make an assessment decreased.

Participatory design improved the observed design satisfaction as well as the common ground among the participants statistically significantly. We can therefore conclude that the participatory design approach did in fact have a positive influence on the design satisfaction and internal agreement within the group in case 2 .

\subsubsection{Satisfaction with the session}

The evaluation showed that the participants were very satisfied with this particular form of participatory design.

- All respondents indicated that the travel to Groningen had been worthwhile

- In case 1 the distance there and back was $400 \mathrm{~km}$ and in case 2 it was $100 \mathrm{~km}$

- In case 1 the general satisfaction with the visit was an 8.1 and in case 2 an 8.7

It can be concluded that the participatory design session provided a positive and useful basis for a discussion about organizational space and the confirmation or refutation of the design decisions made.

The respondents gave their arguments for this judgment (see Table 2 for details). The table shows that all comments were positive; only nine respondents did not give additional comments. The participants argued that this particular form of participatory design added value to both the design and the design process. It allowed the participants to catch a glimpse of their future; the design became very alive. The approach increased their understanding and their commitment. This increased insight allowed the designers to assess their own work critically and also stimulated the workers' emancipation. The consequences of the design were easy to understand. Workers could actively participate in the design discussion, critically assess the qualities of the design, question the design principles and decisions made, and even decide to change the design whenever necessary. This broad involvement and openness in eliminating design mistakes had clear benefits. It improved the understanding and the commitment in the organization with respect to the final design, which in turn may have increased the general satisfaction with it. 
Table 2 Comments of the respondents on the quality of the participatory design session

\begin{tabular}{|c|c|c|}
\hline Case & Respondent & Comment \\
\hline \multirow[t]{7}{*}{1} & 1 & Everything has become clearer now. \\
\hline & 2 & More insight into how things function and the possibilities to change things. \\
\hline & 3 & $\begin{array}{l}\text { 3D pictures were interesting and clear. Now I have more insight into how it will be. We } \\
\text { have come to certain conclusions, we discussed, made changes etc. Awfully nice! }\end{array}$ \\
\hline & 4 & To see walking lines. \\
\hline & 5 & $\begin{array}{l}\text { 3D support, the design comes alive. Much time for group discussion (should have done } \\
\text { this earlier/more often, before out visit to Groningen). Just in time for possible } \\
\text { changes, fortunately. }\end{array}$ \\
\hline & 6 & $\begin{array}{l}\text { Spatial representation provides a better insight than drawing. Therefore it is easier to } \\
\text { make changes and estimations. }\end{array}$ \\
\hline & 7 & One can see the direct consequences of the interventions. \\
\hline \multirow[t]{15}{*}{2} & 1 & Providing an image of reality not only based on paper. \\
\hline & 2 & It adds an image to the drawing of the architect. Wonderful technique! \\
\hline & 3 & I have a better idea of how the pharmacy will be now, I feel more tied to the design!! \\
\hline & 4 & Insight into how it will be. Now it all becomes real. Nice. \\
\hline & 5 & I now see what it will be like. Good representation of the new pharmacy. \\
\hline & 6 & $\begin{array}{l}\text { Provides more insight into the layout, much clearer than the sole drawing. The } \\
\text { possibilities to change the drawers and the puppets that walk around, wonderful. }\end{array}$ \\
\hline & 7 & $\begin{array}{l}\text { The virtual theatre was beautifully made. It gives one a much clearer image of how it } \\
\text { will become. The discussion was also good. }\end{array}$ \\
\hline & 8 & Nice. It provides us with a good impression of the future pharmacy. \\
\hline & 9 & Good to form an impression of the new pharmacy. \\
\hline & 10 & Wonderful, I now have a good impression of how the pharmacy will look like. \\
\hline & 11 & It was good for establishing an image. \\
\hline & 12 & Nice to actually 'walk' through the pharmacy. \\
\hline & 13 & $\begin{array}{l}\text { Now I have clear image of how the new pharmacy will look like. Especially the } \\
\text { proportions were clearly visible. }\end{array}$ \\
\hline & 14 & Much better image. \\
\hline & 15 & $\begin{array}{l}\text { It is not only a toy, but a real method to assess the design critically, providing an image } \\
\text { of how the new pharmacy will look like. A real plus in comparison with the drawing. }\end{array}$ \\
\hline
\end{tabular}

\section{Discussion}

The combination of participatory design with virtual worlds for organizational space resulted in positive effects in both cases. The participants of the design session, management, architects, and workers, were all included in the design discussion, resulting in a broad participation. It allowed workers at all levels and with different backgrounds to give their opinion. To the staff of the working floor the virtual session was a very important moment to exchange ideas with the management and the architect, and also to influence the design in real time. They were given power that they had not experienced before in the design process, at least not to this extent. To the management and the architect it was also an important moment: a first test of the quality of the design. Future users would be able to see and experience the quality of their design work. Was it really as good as they thought? 'The proof of the pudding is in the eating' certainly applied here; if the taste of the virtual pudding was not yet at its optimum, its ingredients could still be changed so the real pudding would be perfect.

Moreover, this particular form of participatory design offered a broad understanding of the different perspectives, arguments, and design decisions and made it possible for the organization to build on commitment. In case 1 , this approach increased the involvement of the workers in the design debate more than ever before. From the very start the designers took a top-down approach to create the design. Practically, this approach can be considered as a logical choice because their design was intended for the whole Dutch market. However, what could be considered a negative side effect was that it involved a critical design evaluation, leading to negative attitudes of some workers. In case 2 , participatory design merely served as the finishing touch, as the management had organized the full participation earlier in the design process. The workers were heavily involved, enthusiastic and critical, and VR allowed them to squeeze out the maximum. In addition, the 
participatory design approach presented here is relatively cheap, since it absorbed less than $4 \%$ of the total construction costs. Finally, it can be added that the considerable amount of $41,783 €$ of reconstruction costs after completion of the building was avoided, resulting in the observed net benefits of $12,417 €$.

\section{Conclusion}

It seems safe to conclude that the participatory design approach, combining virtual worlds with organizational space, is a meaningful, valuable, and affordable approach to co-create better organizational spaces. FArMa gave the future inhabitants of a real pharmacy the opportunity to scrutinise the architectural and organizational designs, redefine the design according to their specific needs and wishes and by doing so, increase their commitment and satisfaction with the design, and even reduce costs.

This particular form of participatory design was inspiring and could be used in combination with all sorts of facts and figures related to the current state and expected future state of organizations. Rather than limiting the participants' creativity, this approach boosted their inventiveness in the final phase of the design process. For organizational and architectural sciences these developments may be an interesting opportunity to strengthen their relation with practice. Virtual environments strongly appeal to practitioners and may guide us to a new method of inquiry. Managerial decision makers engaged in the construction and re-construction of their premises should be aware that a combination of organizational science with immersive virtual reality creates a relevant level of participation and facilitates the improvement of the quality of the building designs. In this way the decision makers are capable of expanding their sphere of influence to areas formerly inaccessible to them, such as the field of interior design.

However, we also have to be cautious. A simple lay discussion of design images does not really help the manager. Virtual reality requires organizational sub-titles: facts and values that explain or question why a possible future design may or may not be worthwhile implementing. Moreover, in the case of FArMa the multi-agents' behaviour followed simple patterns. Normally the term agent refers to virtual characters that perform activities on their own. In this case, the agents were card-board puppets, and most of their movements were prefixed XYZ-positions in the design. New software should advance the realism of multi-agent behaviour for this purpose. More studies will have to be conducted to improve the use of VR for this particular form of participatory design. These studies should focus on:
- developing libraries with agents that are relevant to a particular virtual organizational space,

- searching and defining the most fruitful discussion structures and stimuli for VR,

- determining architectural decisions with a positive impact on organization processes and performance.

Acknowledgments I thank Prof. Dr. C.J. de Blaey and Dr. F.J. van der Vaart of the Scientific Institute for Dutch Pharmacists (WINAp), the board of the Royal Dutch Association for the Advancement of Pharmacy (KNMP), and the board of the stichting Nicolaas Muleriusfonds for their financial support of this project. Further, I thank the HPC/V and the unit for application development at the University of Groningen, my research assistants, the pharmacy staff of the two pharmacies involved, and the organizations Orbit architects at Almere, Profarmaplan architects at Breda, AMP at Vught, Argo at Groningen, CLA at Drachten, Netherlands board for hospital facilities in Utrecht, NP/CF in Utrecht, and Peutz at Zoetermeer for their work and valuable support in this project. Finally, I thank the referees for their valuable comments.

Open Access This article is distributed under the terms of the Creative Commons Attribution Noncommercial License which permits any noncommercial use, distribution, and reproduction in any medium, provided the original author(s) and source are credited.

\section{References}

Achten, HH, Turksma A (1999) Virtual reality in early design: the design studio experiences. In: AVOCAAD second international conference

Ackoff RL (1999) Re-creating the corporation -a design of organizations for the 21st Century. Oxford University Press, New York

Airey J, Rohlf J, Brooks FP (1990) Towards image realism with interactive update rates in complex virtual building environments. In: Proceedings of 1990 symposium on interactive 3D graphics 24(2):41-50

Al-Kodmany K (2002) Visualization tools and methods in community planning: from freehand sketches to virtual reality. J Plann Literat 17(2):189-211

Brooks FP (1989) UNC walkthrough. In: SIGGRAPH '89, course 29 implementing and interacting with real-time microworlds

Büscher M, Gill S, Mogensen P, Shapiro D (2001) Landscape of practice. Comput Support Coop Work J Collaborative Comput 10(1):1-28

Brogan DC, Metoyer RA, Hodgins JK (1998) Dynamically simulated characters in virtual environments. IEEE Comput Graph Appl 18(5):58-69

Bruno F, Mattanò RM, Muzzupappa M, Pina M (2005) A new approach to participatory design: usability test in virtual environment. In: Fischer X, Coutellier D (eds) Research in interactive design. Springer, Paris

Campbell DA, Wells M (1994) A critique of virtual reality in the architectural design process. University of Washington, Seattle. http://www.hitl.washington.edu/publications/r-94-3/ (June 2007)

Clarkson JP, Melo A, Eckert C (2000) Visualization of routes in design process planning. In: Proceedings of IV2000 IEEE international conference on information visualization, Brussels

Conway ML, Giuliano Z (1995) Virtual architecture. McGraw-Hill, London 
Davies RC (2004) Adapting virtual reality for the participatory design of work environments. Comput Supp Coop Work J Collaborative Comput 13(1):1-33

Ehn P, Brattgård E, Dalholm RC, Davies A, Hägerfors, Mitchell B, Nilsson J (1996) The envisionment workshop -from visions to practice. In: Proceedings of the participatory design conference. MIT Press, Boston

Fisher X, Coutellier D (eds) (2005) Research in interactive design: proceedings of virtual concept 2005. Springer, Paris

Fisher X, Coutellier D (2007) Editorial. Int J Interact Des Manufact $1(1): 1-4$

Frazer JH (1995) The architectural relevance of cyberspace. In: Pearce M, Spiller N (eds) Architects in cyberspace. Wiley, Chichester

Frazer JH (1998) The co-operative evolution of buildings and cities. In: Streitz NA, Konomi S, Burkhardt HJ (eds) Cooperative buildings integrating information, organization and architecture. Lecture notes in computer science. Springer, Berlin

Fröst P, Warren P (2000) Virtual reality used in a collaborative architectural design process. In: Proceedings of IV2000 IEEE international conference on information visualization. IEEE Computer Society, Brussels

Furness TA (1987) Designing in Virtual Space. In: Rouse, WB, Boff KR (eds) System design: behavioral perspectives on designers, tools, and organizations. North Holland, New York, pp 127-143

Greenburg DP (1991) Computers and architecture. Sci Am 264(2):104-109

Jackson M (2000) Systems approaches to management. Kluwer/ Plenum, New York

Jayaram S, Jayaram U, Jun Kim Y, DeChenne Ch, Lyons KW, Palmer C, Misui T (2007) Industry case studies in the use of immersive virtual assembly. Virtual Real. http://www.springerlink.com/ content/1359-4338 (June 2007)

Karaseitanidis I, Amditis A, Patel H, Sharples S, Bekiaris E, Bullinger A, Tromp J (2006) Evaluation of virtual reality products and applications from individual, organizational and societal perspectives-the "VIEW" case study. Int J Human-Comput Stud 64(3):251-266

Lansdown J (1994) Visualizing design ideas. In: MacDonald L, Vince J (eds) Interacting with virtual environments. Wiley, Chichester

Larijnai LC (1993) Architectural walkthrough: the virtual reality primer. McGraw-Hill, New York

Leclercq P, Martin G (2005) Virtual techniques for architecture. In: Fischer X, Coutellier D (eds) Research in interactive design. Springer, Paris

Levy R (1995) Visualization of urban alternatives. Environ Plan B Plan Des 22(3):315-330

Luoma-aho V (2005) Faith-holders of social capital of Finnish public organisations. Dissertation. University of Jyväskylä, Jyväskylä

Lourdeaux D, Stanciulescu B, Fuchs Ph (2005) Collaborative decision in shared environments: airport management application. In: Fischer X, Coutellier D (eds) Research in interactive design. Paris, Springer

Mahoney DP (1994) Walking through architectural designs. Comput Graph World 17(6):22-30

Mcfadzean J (2000) A functional analysis of the role of visualisation in architectural conceptual design. In: Proceedings of IV2000 IEEE international conference on information visualization. IEEE Computer Society, Brussels

Mobach MP (2007) A critical systems perspective on the design of organizational space. Syst Res Behav Sci 24(1):69-90

Mogensen P, Shapiro D (1998) When survival is an issue: PD in support of landscape architecture. Computer Supported Cooperative Work. J Collaborative Comput 7(3/4):187-203

Newby GB (1993) Virtual reality. In: Williams ME (ed) Annual review of information science and technology 28:187-229
North S (2000) Towards a 3d visualisation framework for construction planning with procession. In: Proceedings of IV2000 IEEE international conference on information visualization. IEEE Computer Society, Brussels

O'Mara M (1999) Strategy and place-managing corporate real estate and facilities for competitive advantage. The Free Press, New York

Pialot O, Legardeur J, Boujut J (2006) Model and tools for collaborative design. In: Fischer X, Coutellier D (eds) Research in interactive design, vol 2. Springer, Paris

Pietsch S (2000) Computer visualization in the design control of urban environments: a literature review. Environ Plan B Plan Des 27(4):521-536

Rheingold H (1991) Virtual reality. Summit Books, New York

Rickel J, Johnson W (2000) Task-oriented collaboration with embodied agents in virtual worlds. MIT Press, Boston

Rigot-Müller P (2005) 3-D digital factory and design methods: a case in the automotive industry. In: Fischer X, Coutellier D (eds) Research in interactive design. Springer, Paris

Russel DM, Streitz NA, Winograd T (2005) Building disappearing computers. Commun ACM 48(3):42-48

Safin S, Boulanger C, Leclercq P (2005) A Virtual desktop first evaluations for an augmented design process. In: Fischer X, Coutellier D (eds) Research in interactive design. Springer, Paris

Schmeltzer GTA, Roelen WAH (1995) Virtual reality in architectural design and real estate simulation. In: Proceedings of virtual reality world '95 IDG

Schmitt G (1993) Virtual reality in architecture. In: Thalmann NM, Thalmann D (eds) Virtual worlds and multimedia. Wiley, Chichester

Stoker DF, Fellow GTW (1992). The future design of visual imaging in design and construction. A/E/C SYSTEMS Computer Solutions

Streitz NA, Kameas A, Mavrommati I (eds) (2007) The disappearing computer. Springer, Berlin

Streitz NA, Konomi S, Burkhardt HJ (eds) (1998) Cooperative buildings integrating information, organization and architecture. Lecture notes in computer science. Springer, Berlin

Streitz NA, Siegel J, Hartkopf V, Konomi S (eds) (1999) Cooperative buildings integrating information, organization and architecture. Lecture notes in computer science. Springer, Berlin

Titman M (1995) Zip, zap, zoom: a Z-A of cyberspace. In: Pearce M, Spiller N (eds) Architects in cyberspace. Wiley, Chichester

Tschumi B (1995) Cite de l'architecture. In: Pearce M, Spiller N (eds) Architects in cyberspace. Wiley, Chichester

Tufte ER (1983) The visual display of quantitative information. Graphics Press, Cheshire

Tufte ER (1997) Visual explanations. Graphics Press, Cheshire

Ulrich W (1983) Critical heuristics of social planning. Haupt, Bern

Verrier R (2006) A mind of their own-artificial intelligence software enables animators to create detailed crowds filled with characters that can react autonomously to one another. LA Times, July 28

Warfield JN (1994) A science of generic design: managing complexity through systems design. Iowa State University Press, Ames

Wijk J van, Vries B de (1999) Towards an understanding 3D VR architectural design system. In: Proceedings of twenty workshop on language technology

Whyte J (2002) Virtual reality and the built environment. Architectural Press, Oxford

Wilson JR (1999) Virtual environments applications and applied ergonomics. Appl Ergon 30(1):3-9

Witmer BG, Bailey JH, Knerr BW, Parsons KC (1996) Virtual spaces and real world places: transfer of route knowledge. Int J HumComput Stud 45(4):413-428

Yin RK (2003) Case study research—design and methods. Sage, London

Zahniser RA (1993) Design by walking around. Commun ACM 36(10):115-123 